\title{
PATOLOGIA CLÍNICA EM AVES DE PRODUÇÃO - UMA FERRAMENTA PARA MONITORAR A SANIDADE AVÍCOLA - REVISÃO
}

\section{(Clinical pathology in poultry - A tool to improve poultry health - a review)}

\author{
SCHMIDT, E. M. S. ${ }^{1}$; LOCATELLI-DITTRICH, R. ${ }^{2}$; SANTIN, E. ${ }^{2}$ PAULILLO, A.C. ${ }^{3}$
}

1. Aluna do Curso de Pós-graduação em Medicina Veterinária - Patologia Animal, FCAV - UNESP, Campus de Jaboticabal. Professora Faculdades Integradas "Espírita", Curso de Zootecnia. Bolsista CNPq - Brasil

2. Departamento de Medicina Veterinária, UFPR. Curso de Pós-graduação em Ciências Veterinárias -

UFPR, Curitiba.

3. Departamento de Patologia Veterinária, FCAV - UNESP, campus de Jaboticabal

\begin{abstract}
RESUMO - A patologia clínica é usada na medicina veterinária há muitos anos para avaliar as alterações metabólicas que possam indicar algum sinal de doença nos animais. Apesar do uso dos parâmetros laboratoriais ser rotina em animais de companhia, não são comumente utilizados para avaliação clínica de aves selvagens ou de produção. A ausência de informações sobre valores sanguíneos de referência limitou o uso destas ferramentas na medicina de aves. Os parâmetros laboratoriais na medicina de aves são úteis para avaliar aspectos relacionados à saúde animal. Desta forma, assim esta revisão apresenta formas de utilização da patologia clínica (hematologia e bioquímica clínica) para auxílio na avaliação e monitoramento da saúde das aves.
\end{abstract}

Palavras-chave: aves; hematologia; bioquímica clínica; sangue.

\begin{abstract}
Clinical pathology has been used in veterinary medicine for many years to evaluate metabolic changes that may indicate any sign of disease in animals. Even though the use of blood parameters is routine in companion animals, it is not commonly used for avian clinical evaluation either wild or production birds. Among others, the lack of information of avian blood reference values has limited the use of this tool in avian medicine. The blood parameters in avian medicine are helpful to evaluate aspects related to animal health for wild and also production birds. Thus, this review paper presents some ways to use clinical pathology parameters to evaluate and to monitor the avian health.
\end{abstract}

Key-words: avian blood; hematology; clinical biochemistry; blood. 


\section{INTRODUÇÃO}

A clínica e a cirurgia de aves são reconhecidamente uma especialidade na medicina veterinária de animais selvagens. Os sinais clínicos em aves são geralmente inespecíficos e a informação obtida pelo exame físico é limitada (LUMEIJ, 1997).

As provas laboratoriais do sangue podem servir como ferramentas importantes para auxiliar no monitoramento da saúde das aves, no diagnóstico de doenças e também para avaliação pré-operatória, tratamento e das condições de saúde do organismo.

Além da possibilidade de se utilizar as provas hematológicas e bioquímicas do sangue na clínica de aves selvagens, há possibilidade se intensificar o uso destas ferramentas no auxílio diagnóstico de enfermidades em avicultura, pois, paralelamente ao crescimento da atividade avícola, ocorreu grande desenvolvimento dos métodos de diagnóstico e de profilaxia das enfermidades aviárias. No entanto, aspectos básicos relacionados à fisiologia e avaliações clínico-laboratoriais são pouco estudados.

O sangue é essencial para manutenção do equilíbrio de eletrólitos e água, para o controle da temperatura e para o funcionamento do sistema imunológico, que é o mecanismo de defesa do organismo (VOIGT, 2003).

Os valores sangüíneos podem ser influenciados pelo estado nutricional, sexo, idade, habitat, estação do ano, estado reprodutivo, trauma, criação e estresse ambiental (CAMPBELL, 2004; THRALL, 2004). Por isso é necessário conhecer essas variações no momento de avaliar os parâmetros sanguíneos na clínica de aves.

A aplicação mais usual da hematologia é para monitorar a saúde geral do animal e avaliar sua capacidade para transportar oxigênio e defenderse contra os agentes infecciosos (VOIGT, 2003). A hematologia objetiva estabelecer um diagnóstico, definir linhas de ação, orientar no prognóstico e tratamento das doenças. O hemograma é um exame laboratorial de rotina que avalia a quantidade e qualidade das células sangüíneas e os trombócitos. Por outro lado, a avaliação bioquímica de alterações dos metabólitos do sangue, tais como proteínas, ácido úrico, colesterol e outros, podem indicar o estado de funcionamento de órgãos como o fígado, os rins, os músculos, entre outros.

O perfil hematológico e bioquímico do sangue é utilizado para acessar o estado fisiológico dos pacientes (CAMPBELL, 2004). Os exames laboratoriais do sangue ajudam, muitas vezes, o médico veterinário a diagnosticar precocemente quadros de sintomatologia subclínica. Alguns autores destacam que o seu pequeno uso na prática veterinária ocorre, em muitos casos, por deficiência de observações sobre os valores hematológicos e bioquímicos no sangue das espécies animais, o que não permite adequada interpretação dos resultados obtidos (BIRGEL, 1982; KANEKO et al., 1997).

Nesta revisão serão abordados os exames hematológicos e os exames bioquímicos, de acordo com o sistema ou órgão, indicações, causas e interpretações das alterações dos exames.

\section{COLHEITA DE SANGUE}

Em aves sadias, a quantidade de sangue que pode ser coletada é, em geral o equivalente a $1 \%$ do peso do animal. Em patos e pombos até 3\% do peso corporal, $2 \%$ em frangos e $1 \%$ em corvos e faisões. Em animais doentes, o máximo que se pode coletar, com segurança, é $1 \%$ do peso corporal (LUMEIJ, 1997). Os principais locais de coleta de sangue são: veia jugular, veia ulnar, veia metatársica medial, seio venoso occipital e punção cardíaca (LEWANDOSWSKI et al., 1986; FUDGE, 2000a).

\section{HEMATOLOGIA}

Para o hemograma é necessário obter amostras de sangue em tubos contendo ácido diaminotetracético (EDTA) como anticoagulante. A heparina também pode ser utilizada para análises hematológicas. Visando prevenir a ocorrência de hemólise, a amostra de sangue deve ser homogeneizada e pode ser refrigerada por um tempo máximo de 24 horas. Os esfregaços sanguíneos devem ser realizados até uma hora após a colheita do sangue. Quando se utiliza heparina, é fundamental que os esfregaços sanguíneos sejam confeccionados no momento da colheita, para evitar alterações na morfologia das células. (ZINKL, 1986; KRAFT, 1998).

As provas laboratoriais que compõem o hemograma das aves são: contagem total de eritrócitos e de leucócitos em hemocitômetro de Neubauer com diluição em azul de toluidina $0,01 \%$, determinação do hematócrito, pela técnica do microhematócrito e dosagem da concentração de hemoglobina. A contagem diferencial de leucócitos é realizada em esfregaços sangüíneos corados com corante hematológico de Wright. Na contagem são diferenciados os heterófilos, linfócitos, eosinófilos, monócitos e basófilos. Na lâmina do esfregaço deve ser observada a presença de parasitos intra-eritrocitários ou intra-leucocitários, além de alterações tóxicas nos leucócitos e também respostas de anemias, como a presença de eritrócitos jovens e policromatofilia, e contagem de trombócitos. Os índices hematimétricos volume globular médio (VGM) e concentração 
hemoglobina globular média (CHGM) são obtidos pelas fórmulas de WINTROBE (1932).

\subsection{Eritrograma}

Os eritrócitos maduros são células ovais ou elípticas com um núcleo central que acompanha a forma da célula, coloração púrpura escuro com cromatina agrupada e uniforme. O citoplasma é abundante e de coloração róseo-alaranjado uniforme, semelhante a dos mamíferos (BOUNOUS e STEDMAN, 2000).

O hematócrito normal das aves varia de 35 a $55 \%$. Valores inferiores a $35 \%$ indicam anemia e superiores a $55 \%$ sugerem desidratação ou policitemia (BOUNOUS e STEDMAN, 2000). O hematócrito também pode sofrer alterações em relação ao sexo e à idade das aves (SCHMIDT et al., 2007). As fêmeas de faisão-de-coleira, papagaio-de-peitoroxo e de cuiú-cuiú apresentam valores menores da série vermelha em relação aos machos, pois os estrógenos tendem a deprimir a eritropoese e os andrógenos promovem o efeito inverso (SCHMIDT et al., 2003; THRALL, 2004; SCHMIDT et al., 2006a; SCHMIDT et al., 2007). Nas micotoxicoses, pode ocorrer aumento moderado nos parâmetros eritrocitários devido a hemoconcentração causada pelo estado de desidratação (em conseqüência da depleção de água do plasma pela emese e ingestão hídrica insuficiente) (PEROZO et al., 2003). A anemia é evidenciada pela diminuição na contagem total de eritrócitos, na diminuição do hematócrito e das concentrações de hemoglobina. Anemias por deficiências já foram registradas em aves domésticas, mas raramente são reconhecidas em aves selvagens/exóticas de cativeiro, pois o ferro está presente nos produtos utilizados para alimentação destas aves (FUDGE, 2000a).

$\mathrm{Na}$ anemia severa, a forma do eritrócito pode apresentar alterações, as células aparecendo redondas e com núcleo oval. Isto é sugestivo de uma maturação sem sincronia do núcleo da célula e do citoplasma, provavelmente devido a eritropoese acelerada (DEIN, 1986; ZINKL, 1986). As principais causas de anemia nas aves são: traumas, parasitismo, intoxicações (aflatoxicose, chumbo), sepsis bacteriana (salmonelose), neoplasias e parasitas de eritrócitos (Plasmodium aegyptianella), imunomediada, doenças crônicas (DEIN, 1986; FUDGE, 2000a). A exposição subclínica a aflatoxinas promove perdas na indústria avícola devido à diminuição da resposta imune e anemia (PEROZO et al., 2003).

\subsection{Leucograma}

O número de leucócitos totais e a morfologia destas células são estáveis no animal sadio, mas pode variar de acordo com a idade e o sexo das aves (SCHMIDT et al., 2006a; SCHMIDT et al., 2007). O leucograma pode sofrer alterações drásticas nas doenças, permitindo acessar a resposta imunológica dos animais.

Os leucócitos granulócitos são: heterófilos, eosinófilos e basófilos. Os linfócitos e monócitos são os leucócitos agranulócitos. O heterófilo apresenta citoplasma sem coloração, com grânulos laranjaavermelhados ovais ou em forma de fuso e núcleo violeta lobulado. O citoplasma dos eosinófilos é azul e contêm grânulos vermelho-alaranjados e redondos, que se coram mais brilhantes ou diferentes dos grânulos dos heterófilos. O núcleo do eosinófilo também é lobulado e violeta (BOUNOUS e STEDMAN, 2000; THRALL, 2004). O basófilo é levemente menor do que o heterófilo e tem o citoplasma sem cor e com grânulos púrpura escuro. O núcleo do basófilo é púrpuro e não-lobulado (DEIN, 1986; BOUNOUS e STEDMAN, 2000).

Os linfócitos são células redondas com núcleo não-lobulado e púrpura escuro com citoplasma homogêneo azul claro. Os monócitos são os maiores leucócitos encontrados no sangue periférico. Apresentam citoplasma delicadamente granular, abundante e azul-acinzentado, com núcleo púrpura (BOUNOUS e STEDMAN, 2000; THRALL, 2004).

As causas do aumento do número total de leucócitos (leucocitose), são: infecção geral ou localizada, traumas, intoxicação, hemorragia em cavidade, neoplasias de crescimento rápido e leucemias. A heterofilia ocorre geralmente devido à inflamação. $A$ leucocitose leve a moderada, com heterofilia e linfopenia indica resposta ao estresse com excesso de glicocorticóide endógeno ou exógeno (DEIN, 1986; LATIMER e BIENZLE, 2000; THRALL, 2004).

Os heterófilos segmentados são encontrados normalmente na maioria das extensões sanguíneas. Os heterófilos imaturos bastonetes são liberados da medula óssea quando ocrre um processo inflamatório. $\mathrm{O}$ aumento no número de heterófilos imaturos caracteriza o desvio à esquerda $O$ desvio à esquerda ocorre principalmente na infecção bacteriana severa, micobacteriose, aspergilose, clamidiose e necrose tecidual severa resultante de trauma ou neoplasia. A presença de heterófilos tóxicos sugere toxemia. Quanto maior o grau de toxicidade, pior o prognóstico (FUDGE e JOSEPH, 2000; LATIMER e BIENZLE, 2000). 
Os heterófilos tóxicos com vacuolizações citoplasmática, picnose nuclear, cariólise, basofilia citoplasmática e alteração dos grânulos citoplasmáticos foram encontrados em casos de alterações hepáticas por agente não-infeccioso em codornas de criação industrial (LOCATELLI-DITTRICH et al., 2000). PEROZO et al. (2003) observaram linfopenia com heterofilia e monocitose em frangos com micotoxicose. Podem ocorrer, nas aves, distúrbios na atividade fagocitária dos heterófilos e também inibição da atividade fagocitária dos monócitos (CHANG e HAMILTON, 1979).

A leucopenia (diminuição número total de leucócitos) corre por depressão da leucopoiese ou por diminuição dos leucócitos periféricos. A leucopenia com heteropenia ocorre em algumas doenças virais e infecção bacteriana de grande extensão (septicemia). Quando associada com heterófilos imaturos sugere exaustão do pool de reserva dos heterófilos maduros, devido a grande necessidade (DEIN, 1986; BOUNOUS E STEDMAN, 2000; FUDGE e JOSEPH, 2000; LATIMER e BIENZLE, 2000). A vacinação contra a coccidiose em frangos de corte induz à redução no número total de leucócitos por estimular uma resposta inflamatória local. A vacinação induz a migração dos leucócitos para a mucosa intestinal, que é o local da infecção vacinal (SCHMIDT et al., 2006b).

A heteropenia não é comum nas aves. Alinfopenia ocorre em certas doenças virais, mas é pouco documentada nas aves. Ocorre em infecções sistêmicas agudas ou estresse severo. A linfocitose aparece em condições de estímulo antigênico associado com infecções crônicas (bacteriana, viral, fúngica ou parasitária) e também neoplasia linfóide (linfossarcoma ou leucemia linfóide, com até 200.000 linfócitos $/ \mu \mathrm{L}$ ). A presença de linfócitos reativos no esfregaço sangüíneo sugere estímulo antigênico. A linfocitose fisiológica representa um fenômeno transitório nas aves após excitação, medo ou "luta" durante o procedimento de retirada do sangue (LATIMER e BIENZLE, 2000). A monocitose geralmente está associada a doenças crônicas como em lesões granulomatosas micóticas e bacterianas, necrose tecidual inespecífica, aspergilose, dermatite bacteriana crônica, salmonelose, tuberculose, clamidiose ativa ou crônica e por deficiência de zinco na dieta (DEIN, 1986; FUDGE e JOSEPH, 2000; LATIMER e BIENZLE, 2000). No entanto, a monocitose também é observada nos distúrbios agudos, em até 12 horas após a instalação da inflamação. A monocitopenia não tem importância clínica.

A basofilia ocorre em doenças respiratórias e em lesões teciduais severas. Está associada também com estresse e parasitismo interno e externo, geralmente acompanhada de eosinofilia (LATIMER e BIENZLE, 2000; SCHMIDT et al., 2007). As causas de eosinofilia são edema facial e parasitismo. A eosinopenia está associada a estresse severo e administração de corticoesteróides (BOUNOUS e STEDMAN, 2000; LATIMER e BIENZLE, 2000).

O clínico deve interpretar os dados hematológicos para avaliar as possíveis alterações patológicas no paciente. Estas alterações patológicas geralmente não definem o diagnóstico final ou a etiologia. Por exemplo, a inflamação pode ser confirmada pelos resultados do hemograma, porém, exames adicionais serão necessários para localizar a inflamação e a sua causa.

\subsection{Trombócitos}

Apesar da contagem de trombócitos não ser realizada como rotina, estas células podem participar de funções de defesa do organismo, além da participação na coagulação sangüínea. São derivados de uma linhagem distinta de células encontradas no tecido hematopoiético. Os trombócitos apresentam o citoplasma sem coloração e com grânulos vermeIhos. O núcleo é púrpura escuro. Os valores normais variam entre 20.000 a $30.000 / \mu \mathrm{L}$ ou 10 a $15 / 1000$ eritrócitos (BOUNOUS e STEDMAN, 2000)

A trombocitopenia ocorre em formas pancitopênicas de doenças virais. Alterações no tempo de coagulação também podem ser observadas em aves (FUDGE, 2000a) e também quando há grande necessidade periférica de trombócitos ou uma depressão da trombopoiese (DEIN, 1986).

\subsection{Hemoparasitos e inclusões celulares}

As inclusões em leucócitos de aves não são comuns, mas quando encontradas fornecem um diagnóstico definitivo. Os exemplos de inclusões são: bactéria fagocitada em heterófilos de aves com septicemia, Atoxoplasma sp. no citoplasma de monócitos, Leukocytozoon sp. no citoplasma de eritrócitos ou leucócitos de aves de rapina e aves aquáticas. Os corpúsculos elementares de Chlamydophilla psittaci podem ser encontrados no citoplasma dos leucócitos (LATIMER e BIENZLE, 2000; FUDGE e JOSEPH, 2000; THRALL, 2004).

Os parasitos de eritrócitos mais comuns são: Plasmodium sp., que pode provocar mortalidade principalmente em canários, falcões e pombos. $\mathrm{O}$ gênero Haemoproteus sp. tem ampla distribuição numa variedade de espécies de aves. A Aegyptianella $\mathrm{sp}$, uma rickétsia, pode ser observada no interior de eritrócitos, no entanto, são poucos os registros da doença clínica. Nos esfregaços de sangue periférico podem ser encontradas microfilárias (FUDGE, 2000a). 


\section{BIOQUIIMICA CLÍNICA}

\subsection{Amostras}

A maioria das análises bioquímicas é realizada no plasma ou no soro. Como a coleta de soro das aves freqüentemente resulta numa amostra pequena, prefere-se o plasma para avaliações de provas bioquímicas de rotina. A heparina é o anticoagulante de escolha (CAMPBELL, 2004). Amostras com EDTA (ácido etilenodiaminotetracético) não são apropria- das para provas enzimáticas porque este anticoagulante é quelante de íons que podem ser necessários para a atividade enzimática (LUMEIJ, 1997).

Apesar da lipemia interferir nas análises, a obtenção de amostras de jejum é tarefa complicada nas aves, pois animais enfermos não devem ser privados de alimentos. Além disso, considerandose a natureza da anatomia e fisiologia digestiva destes animais, é difícil a obtenção de um estado de jejum seguro (CAMPBELL, 2004). Os principais exames bioquímicos utilizados para as aves estão na TABELA 1.

\section{TABELA 1 - PRINCIPAIS PROVAS BIOQUÍMICAS EMPREGADAS PARA AS AVES E CONDIÇÕES DE ACONDICIONAMENTO.}

\begin{tabular}{|c|c|c|c|c|}
\hline \multirow{3}{*}{ Provas bioquímicas } & \multicolumn{3}{|c|}{ Amostras } & \multirow{3}{*}{ Estabilidade da amostra } \\
\hline & \multirow[b]{2}{*}{ Soro } & \multicolumn{2}{|c|}{ Plasma } & \\
\hline & & EDTA & Heparina & \\
\hline Alanina aminotransferase (ALT) & $x$ & & $\mathrm{x}$ & $\begin{array}{l}0 \text { a } 4^{\circ} \mathrm{C} \text { (8 dias); } \\
\text { congeladas (8 dias) }\end{array}$ \\
\hline Aspartato aminotransferase (AST) & $\mathrm{x}$ & $\mathrm{x}$ & $\mathrm{x}$ & $\begin{array}{l}0 \text { a } 4^{\circ} \mathrm{C} \text { (8 dias); } \\
\text { congeladas (4 dias) }\end{array}$ \\
\hline Gama-glutamiltransferase(GGT) & $x$ & $\mathrm{x}$ & $x$ & $\begin{array}{l}4 \text { semanas } \mathrm{a}-20^{\circ} \mathrm{C}, \\
12 \text { dias de } 2 \text { a } 8^{\circ} \mathrm{C}\end{array}$ \\
\hline Fosfatase alcalina (AP) & $x$ & $x$ & $x$ & $\begin{array}{l}0 \text { a } 4^{\circ} \mathrm{C} \text { ( } 8 \text { dias); congeladas } \\
30 \text { dias a }-10^{\circ} \mathrm{C}\end{array}$ \\
\hline Glutamato desidrogenase (GLDH) & $\mathrm{x}$ & & & $\begin{array}{l}0 \text { a } 4^{\circ} \mathrm{C} \text { ( } 4 \text { dias); congeladas } \\
\text { (8 dias) }\end{array}$ \\
\hline Sorbitol desidrogenase (SDH) & $x$ & & & Dosar imediatamente \\
\hline Bilirrubinas & $x$ & & & $\begin{array}{l}\text { Proteger da luz, e dosar o } \\
\text { mais rápido possível, estável } \\
\text { até } 3 \text { dias entre } 2 \text { a } 8^{\circ} \mathrm{C}\end{array}$ \\
\hline Ácidos biliares & $x$ & & & \\
\hline Creatina-quinase (CK) & $\mathrm{x}$ & & $\mathrm{x}$ & $\begin{array}{l}\left.0 \text { a } 4^{\circ} \mathrm{C} \text { ( } 1 \text { dia }\right) \\
\text { congelada (8 dias) }\end{array}$ \\
\hline Lactato desidrogenase (LDH) & $\mathrm{x}$ & $x$ & $x$ & $\begin{array}{l}2 \text { a } 8^{\circ} \mathrm{C} \text { ( } 2 \text { dias); congelada } \\
\text { (8 dias) }\end{array}$ \\
\hline Glicose* $^{*}$ & $\mathrm{x}$ & & & $\begin{array}{l}\text { Dosar imediatamente no } \\
\text { soro; *plasma com fluoreto } \\
\text { de sódio }\end{array}$ \\
\hline Colesterol & $x$ & $x$ & $\mathrm{x}$ & $\begin{array}{l}2 \text { semanas entre } 2 \text { a } 8^{\circ} \mathrm{C} \text {; } \\
\text { congelada ( } 6 \text { meses) }\end{array}$ \\
\hline Uréia & $x$ & $\mathrm{x}$ & $\mathrm{x}$ & $\begin{array}{l}7 \text { dias entre } 2 \text { a } 8^{\circ} \mathrm{C} ; \\
\text { congelada }\left(-10^{\circ} \mathrm{C}\right) \text { por } 3 \\
\text { meses }\end{array}$ \\
\hline Ácido úrico & $x$ & $\mathrm{x}$ & $\mathrm{x}$ & $\begin{array}{l}2 \text { a } 8^{\circ} \mathrm{C}(3 \text { dias }) \\
7 \text { dias } \mathrm{a}-10^{\circ} \mathrm{C}\end{array}$ \\
\hline Proteínas totais**, albumina & $\mathrm{x}$ & \begin{tabular}{l}
$\quad \mathrm{c}$ \\
\multicolumn{1}{c}{ * Somente } \\
Proteínas \\
plasmáticas \\
totais
\end{tabular} & \begin{tabular}{l}
\multicolumn{1}{c}{$\mathrm{x}$} \\
${ }^{* *}$ Somente \\
Proteínas \\
plasmáticas \\
totais
\end{tabular} & $\begin{array}{l}2 \text { a } 8^{\circ} \mathrm{C} \text { ( } 3 \text { dias); congelada por muitos } \\
\text { meses }\end{array}$ \\
\hline
\end{tabular}




\subsection{Função renal}

As aves possuem dois tipos de néfrons. O néfron tipo "réptil" ou cortical superficial, que não apresenta as alças do néfron e recebe sangue do sistema porta renal. Os néfrons tipo "mamífero" ou medulares profundos apresentam alça do néfron e são envolvidos com o processo do gradiente osmótico de formação de urina. Os rins das aves recebem sangue do sistema porta renal, suprindo aproximadamente dois terços do sangue dos túbulos renais. Este sistema auxilia a secreção do ácido úrico pelos túbulos renais (CAMPBELL, 2004; REECE, 2006).

O ácido úrico e a uréia são as provas bioquímicas utilizadas para avaliar a função renal das aves. $O$ ácido úrico é o principal produto do metabolismo de nitrogênio nas aves, constituindo aproximadamente 60 a $80 \%$ do total de nitrogênio excretado pela urina da ave. É sintetizado no fígado e nos rins, sendo $90 \%$ do ácido úrico sangüíneo excretado primariamente por secreção tubular, nos túbulos proximais dos néfrons corticais. Este processo de secreção é independente da reabsorção tubular de água (CAMPBELL, 2004; LUMEIJ, 1997). Assim, distúrbios na função renal podem levar ao aumento na concentração sérica ou plasmática do ácido úrico (LUMEIJ, 1997).

As concentrações sangüíneas de ácido úrico superiores a $15 \mathrm{mg} / \mathrm{dL}$ sugerem alterações da função renal, que podem ser causadas por diversos fatores, como nefrotoxinas, obstrução urinária, nefrite e nefropatias associadas à hipovitaminose A (AMAND, 1986; CAMPBELL, 2004). Diversos fatores podem influenciar nas concentrações de ácido úrico, como a espécie, idade e dieta. Animais jovens tendem a apresentar maiores concentrações de ácido úrico do que adultos. Aves carnívoras apresentam maiores concentrações do que aves granívoras (CAMPBELL, 2004)

O ácido úrico não é um teste renal sensível em aves, pois, $75 \%$ da função renal deve estar comprometida para que seja possível detectar o aumento da concentração sangüínea. Além disso, as aves podem apresentar hiperuricemia após ingestão de dietas com altos teores de proteínas, ou durante jejum prolongado e na necrose tecidual severa. Apesar dessas limitações, o ácido úrico é útil para monitorar o tratamento e a progressão da doença quando utilizado em determinações seqüenciais (GREGORY, 2003; LIERZ, 2003; CAMPBELL, 2004).

$\mathrm{O}$ ácido úrico apresenta-se elevado em galinhas inoculadas com várias cepas do vírus da doença de Newcastle (RIVETZ et al., 1977). Esta elevação pode ter ocorrido por danos renais, pela diminuição na taxa de eliminação, por alteração na condição nutricional devido a redução da ingestão de alimentos e injúrias no sistema digestório.

A concentração da uréia sanguínea é influenciada pela ingestão de proteínas, pela taxa de excreção renal (que podem aumentar a concentração sangüínea da uréia) e pelo estado do fígado, que é o órgão responsável pela sua síntese. As aves carnívoras têm maiores concentrações de uréia do que aves granívoras (CAMPBELL, 2004; KANEKO et al., 1997). Como as aves são uricotélicas, pequenas quantidades de uréia estão presentes no plasma. A concentração normal de uréia de aves não carnívoras é de 0 a $5 \mathrm{mg} / \mathrm{dL}$ (CAMPBELL, 2004).

Considera-se que a uréia tem pouco valor diagnóstico para as aves quando comparada ao ácido úrico (AMAND, 1986; CAMPBELL, 2004). Contudo, a uréia pode ser um teste sensível para azotemia pré-renal em algumas espécies de aves, porque é eliminada por filtração glomerular, que depende do estado de hidratação do animal. Desta forma, é útil para detectar uma diminuição da perfusão arterial renal (CAMPBELL, 2004; LUMEIJ, 1997).

A creatinina tem pouco valor diagnóstico nas aves porque a creatina é excretada pelos rins antes de ser convertida em creatinina. Assim, o ideal seria dosar as concentrações plasmáticas de creatina para detectar uma diminuição na taxa de filtração glomerular. No entanto, os laboratórios veterinários não possuem um método de rotina para a determinação deste metabólito (LIERZ, 2003; CAMPBELL, 2004).

\subsection{Função hepática}

\subsubsection{Enzimas}

Nas aves, as provas de função hepática estão divididas em testes de enzimas hepáticas, que refletem lesão hepatocelular: aspartato aminotransferase (AST), alanina aminotransferase (ALT), glutamato desidrogenase (GLDH), lactato desidrogenase (LD) e sorbitol desidrogenase (SD) e aumento na produção enzimática conseqüente à colestase ou indução por drogas: gama glutamiltransefase (GGT) e fosfatase alcalina (AP), e metabólitos ou testes funcionais do fígado (colesterol, ácidos biliares e bilirrubinas), glicose e as proteínas.

São escassos os estudos experimentais sobre a sensibilidade e a especificidade das atividades das enzimas séricas ou plasmáticas de função hepática nas aves, sendo limitados a algumas espécies (CAMPBELL, 2004). Da mesma forma que nos mamíferos, as atividades das enzimas podem ser utilizadas para detectar distúrbios hepatocelulares ou aumento de produção. 
O aumento significativo da AST sugere lesão hepática grave e difusa e também distúrbios musculares, pois a AST não é hepato-específica (KANEKO, et al., 1997). As aves apresentam alta atividade da AST no fígado, músculo esquelético e cardíaco, cérebro e rins. No entanto, a distribuição desta enzima nos diferentes tecidos varia de acordo com a espécie (LUMEIJ, 1997; CAMPBELL, 2004).

De maneira geral, valores de AST acima de $275 \mathrm{UI} / \mathrm{L}$ sugerem aumento da sua atividade, que pode estar relacionado a distúrbios hepáticos ou musculares. Os valores de AST acima de $800 \mathrm{UI} / \mathrm{L}$ são altamente sugestivos de dano hepático severo, principalmente na presença de biliverdinúria ou biliverdinemia (CAMPBELL, 2004). Assim, atualmente, a atividade da AST é considerada como um marcador sensível, mas não específico de distúrbio hepatocelular na maioria das aves, e deve ser mensurada juntamente com uma enzima músculo-específica, creatina quinase (CK), para que seja possível diferenciar dano hepático ou muscular.

Os gansos, galinhas e perus apresentam maior atividade da AST no coração, seguido pelo fígado e músculo esquelético (perus - maior atividade nos rins e cérebro do que no músculo esquelético). Os patos apresentam maior atividade da AST no músculo esquelético, coração, rins, cérebro e fígado (LEWANDOWSKI et al., 1986; FUDGE,2000a).

A glutamato desidrogenase (GLDH) está presente nas mitocôndrias dos hepatócitos e é considerada como o marcador mais específico de distúrbios hepatocelulares nas aves (LUMEIJ, 1997), apesar de não ser rotina a dosagem desta enzima. Todavia, não há disponível um método de rotina para a determinação da concentração desta enzima. Outros tecidos também apresentam atividade da GLDH, como cérebro e rins de pombos, galinhas, patos, perus e periquitos. Teores maiores do que $10 \mathrm{UI} / \mathrm{L}$ indicam necrose hepática. A magnitude do aumento é proporcional à severidade da injúria hepatocelular (LUMEIJ, 1997; CAMPBELL, 2004).

A atividade da enzima lactato desidrogenase (LD) não é específica para distúrbio hepatocelular nas aves (CAMPBELL, 2004). No entanto, cinco isoenzimas já foram demonstradas em tecidos das aves (AMAND, 1986).O aumento de seus teores plasmáticos geralmente está associado a distúrbios hepatocelulares ou musculares. Os eritrócitos das aves têm alta atividade da LD, assim, a hemólise resulta em teores elevados de LD no plasma. Em relação à $A S T$ e $A L T$, a atividade plasmática da $L D$ aumenta e diminui mais rápido após danos hepáticos ou musculares (CAMPBELL, 2004). Galinhas têm maior atividade da LD na musculatura esquelética, no miocárdio, fígado e pulmão (FUDGE, 1997; LEWANDOWSKI et al., 1986).
A atividade da alanina aminotransferase (ALT) tem valor limitado como teste para avaliar distúrbios hepatocelulares em aves. Como em eqüinos e ruminantes, a ALT é encontrada tanto no citosol do hepatócito como no músculo e em outros tecidos nas aves. A atividade da ALT na maioria das espécies de aves varia de 19 a 50 UI/L (LUMEIJ, 1997; CAMPBELL, 2004).

A GGT (gama glutamiltransferase) é uma enzima de membrana associada a vários tecidos. Sua atividade sérica ou plasmática elevada ocorre pelo aumento de produção e liberação pelo tecido hepatobiliar (MEYER et al., 1995). No entanto, a atividade plasmática da GGT não aumenta necessariamente em aves com distúrbio hepatobiliar. As aves apresentam atividade da GGT nos rins, cérebro e intestino, entretanto, distúrbios nesses órgãos não alteram os teores plasmáticos desta enzima.

Teores elevados de GGT foram observados em pombos com doença hepática induzida experimentalmente (LUMEIJ, 1997), indicando que a atividade plasmática pode aumentar em algumas espécies dependendo da natureza do distúrbio hepático (CAMPBELL, 2004). Os patos apresentam alta atividade da GGT nos rins. O aumento dos níveis da GGT sanguínea indica lesão hepática ativa, porém, níveis normais não garantem o funcionamento normal do fígado (FUDGE, 2000b). Os valores de GGT entre $0-10 \mathrm{U} / \mathrm{L}$ são considerados "normais". As diferentes metodologias para determinação da GGT podem contribuir para as diferenças nos valores de referência (LUMEIJ, 1997).

A fosfatase alcalina (AP) plasmática nas aves resulta primariamente de atividade osteoblástica. Assim, aumento nos teores desta enzima sugere crescimento ósseo, reparação de fraturas, osteomielites, neoplasias e condição pré-ovulatória de galinhas. Apresenta baixa atividade no tecido hepatobiliar (CAMPBELL, 2004), apesar de teores elevados já terem sido registrados em aves de rapina que apresentavam colestase (AMAND, 1986). As aves apresentam atividade da ALP em diversos tecidos, nos pulmões, músculo esquelético, testículos, ossos, rins, músculo cardíaco e pouca atividade no fígado. Perus têm maior atividade nos testículos e os patos apresentam maior atividade no duodeno e rins (FUDGE, 2000b).

As atividades das enzimas hepáticas alanina aminotransferase (ALT), aspartato aminotransferase (AST) e fosfatase alcalina (FA) estão elevadas, assim como as concentrações séricas de bilirrubinas nos casos de aflatoxicose. As micotoxinas hepatotóxicas promovem o extravazamento das enzimas hepatobiliares AST, ALT e gama glutamiltransferase (GGT) para o sangue das ave, além da elevação dos ácidos biliares, que é um marcador sensível da função hepática nesses animais (LUMEIJ, 1997). 


\subsubsection{Metabólitos}

As bilirrubinas não são indicadores de distúrbios hepatobiliares nas aves, pois estas possuem pequena quantidade da biliverdina redutase, assim, o pigmento biliar primário é a biliverdina. Desta forma, a icterícia é rara. Entretanto, já foi diagnosticada icterícia (clínica) em patos e araras. Neste caso, provavelmente, houve a redução de biliverdina para bilirrubina por enzimas hepáticas inespecíficas ou por bactérias (LEWANDOWSKI et al., 1986; CAMPBELL, 2004).

A presença de biliverdinemia é observada quando o soro ou o plasma apresentam coloração esverdeada, que reflete doença hepatobiliar severa. Não se faz a dosagem de biliverdina porque é um pigmento instável e muito sensível à degradação pela luz. A coloração amarelada do plasma ou soro das aves está associada com pigmentos carotenóides provenientes da dieta e não deve ser confundido como bilirrubinemia (LUMEIJ, 1997; CAMPBELL, 2004). Como as enzimas séricas ou plasmáticas não apresentam sensibilidade e nem especificidade para detectar doenças hepáticas e também não refletem o grau de comprometimento do fígado, são necessários outros testes bioquímicos sangüíneos para avaliar o metabolismo do fígado nas aves. Além disso, como há dificuldade para dosagem de biliverdina, a determinação dos ácidos biliares pode ser uma ferramenta útil para avaliar a função hepática em algumas espécies de aves (CAMPBELL, 2004). No entanto, o kit comercial para dosagem desse metabólito não se encontra disponível no mercado nacional.

Os ácidos biliares são sintetizados no fígado a partir do colesterol, excretados na bile e reabsorvidos pelo intestino para a circulação portal e removidos do sangue pelos hepatócitos (KANEKO et al., 1997). Aves sadias apresentam pequena quantidade de ácidos biliares no sangue periférico. No entanto, os ácidos biliares primários das aves são o ácido quenodesoxicólico, ácido cólico e ácido alocólico. As concentrações de ácidos biliares no jejum são mais baixas do que nas condições pós-prandiais. A concentração de ácidos biliares pós-prandial não varia entre as espécies de aves com ou sem vesícula biliar (CAMPBELL, 2004). O aumento da concentração de ácidos biliares no jejum sugere alterações hepáticas, no seu armazenamento, excreção ou na perfusão do fígado (FUDGE, 1997; LUMEIJ, 1997). Recomenda-se jejum de 12 horas para a dosagem de ácidos biliares, mas em algumas espécies a variação do tempo de esvaziamento do papo torna a amostragem pós-prandial difícil. Para aves carnívoras, o jejum deve ser de 24 horas. Além deste fator, aves enfermas geralmente apresentam diminuição do trânsito gastrintestinal ou estase. E, por outro lado, o aumento da motilidade intestinal interfere com a liberação dos ácidos biliares pelo fígado e a absorção pelo intestino. A concentração plasmática de ácidos biliares nas aves é maior do que nos mamíferos. Em araras, pombos e cacatuas, o valor de referência varia de 18 a $71 \mu \mathrm{mol} / \mathrm{L}$. Para papagaios, os valores variam de 19 a $144 \mu \mathrm{mol} / \mathrm{L}$ (CAMPBELL, 2004) e para avestruzes de 8 a 30 $\mu \mathrm{mol} / \mathrm{L}$ (LUMEIJ, 1997).

O colesterol é um precursor importante dos ésteres de colesterol, dos ácidos biliares e dos hormônios esteróides. Pode ser sintetizado por vários tecidos do organismo, mas o fígado é o órgão principal de síntese endógena de colesterol. A hipercolesterolemia pode ser causada pela dieta ou também por insuficiência hepática (KANEKO et al., 1997). Como o colesterol é eliminado na forma de ácidos biliares, o aumento da sua concentração no plasma pode estar associado com obstrução biliar extra-hepática, fibrose hepática e hiperplasia de ductos biliares nas aves (AMAND, 1986; CAMPBELL, 2004). As concentrações plasmáticas para a maioria das espécies de aves variam de 100 a 250 mg/dL (LUMEIJ, 1997).

\subsubsection{Glicose}

A concentração sangüínea de glicose de aves sadias varia de 200 a $500 \mathrm{mg} / \mathrm{dL}$ e varia de acordo com o ritmo circadiano, até $800 \mathrm{mg} / \mathrm{dL}$ em colibris. Os teores normais de glicose são mantidos por glicogenólise hepática durante períodos curtos de jejum. Períodos prolongados de jejum em aves sadias (até oito dias) não diminuem a utilização de glicose, como nos mamíferos. Durante o jejum, a perda de energia está relacionada com a depleção de gorduras e mobilização de proteínas, resultando em perda de peso, que pode ser observada pela redução da massa muscular peitoral (CAMPBELL, 2004).

Como nos mamíferos, o metabolismo da glicose nas aves é regulado pela insulina e pelo glucagon. Todavia, o glucagon parece interferir de forma significativa nesse metabolismo, o que pode ser explicado pelo fato de que aves granívoras apresentam abundância de células alfa no pâncreas e uma menor proporção insulina:glucagon em relação aos mamíferos. A distribuição das células pancreáticas de aves carnívoras é semelhante à dos mamíferos, assim, o metabolismo da glicose difere entre aves granívoras e carnívoras (LUMEIJ, 1997). A hipoglicemia é observada quando os teores de glicose caem para menos do que $200 \mathrm{mg} / \mathrm{dL}$ e resulta de jejum prolongado, doença hepática severa, septicemia ou distúrbios endócrinos (CAMPBELL, 2004). A demora na separação do soro ou plasma das células não diminui de forma significativa a concentração de 
glicose como nos mamíferos, pois os eritrócitos das aves utilizam ácidos graxos e não glicose para seu metabolismo (AMAND, 1986; CAMPBELL, 2004). A hiperglicemia é caracterizada por concentrações de glicose acima de $500 \mathrm{mg} / \mathrm{dL}$ e ocorre em diabetes mellitus, aparentemente associado com excesso de glucagon por tumores pancreáticos e pancreatites (LUMEIJ, 1997; CAMPBELL, 2004), liberação de catecolaminas e excesso de glicocorticóides por estresse ou administração de corticoesteróides (AMAND, 1986; CAMPBELL, 2004). Em tucanos, a ocorrência de diabetes mellitus é significativa e está, aparentemente, relacionada com frutas da dieta (CAMPBELL, 2004; FUDGE, 2000b).

O perfil de frangos de corte acometidos por sinais compatíveis com síndrome ascítica mostrou depressão do metabolismo energético (depressão das fontes de energia, pois o animal vai perdendo o apetite gradativamente, devido à pressão causada pelo edema abdominal), evidenciado pela diminuição da glicose, colesterol e triglicerídeos (GONZÁLEZ et al., 2001).

\subsubsection{Proteínas}

As concentrações das proteínas plasmáticas totais nas aves são menores do que nos mamíferos, variando de 2,5 a $4,5 \mathrm{~g} / \mathrm{dL}$. A albumina representa de 40 a $50 \%$ da proteína plasmática total das aves (teores normais variam de 0,8 a $2,0 \mathrm{~g} / \mathrm{dL}$ ) e é sintetizada no fígado. Importante lembrar que a albumina se liga e transporta ânions, cátions, ácidos graxos, hormônios (KANEKO et al. 1997). Assim, a hipoalbuminemia também afeta as concentrações desses compostos. De forma geral, os principais fatores que afetam as concentrações das proteínas totais nas aves são: idade, sazonalidade, condições de criação (manejo) e doenças (LUMEIJ, 1997).

As imunoglobulinas produzidas por linfócitos $B$ e plasmócitos representam um componente significativo na concentração das proteínas plasmáticas totais (CAMPBELL, 2004).

A produção de ovos pode afetar as concentrações das proteínas totais (albumina e globulinas). As proteínas são precursores da gema (vitelogenina e lipoproteínas), sintetizadas no fígado e transportadas para o ovário onde são incorporadas ao oócito no ovário. As fêmeas antes da postura podem apresentar hiperproteinemia induzida por estrógenos (CAMPBELL, 2004; LUMEIJ, 1997), fato já observado em fêmeas adultas de faisão-de-coleira em estação reprodutiva (SCHMIDT et al., 2006a; SCHMIDT et al., 2007).

Em relação ao método de dosagem das proteínas plasmáticas, há discordância na literatura. Para alguns autores o método do biureto é o ideal (CAMPBELL, 2004); no entanto, estudos realizados em frangos, perus e patos, revelaram uma boa correlação entre o método do refratômetro e do biureto (ANDERSON, 1989), apresentando essas espécies menores teores de glicose sangüínea em relação aos psitacídeos e às aves de pequeno porte.

As concentrações de proteínas plasmáticas obtidas pelo método do biureto combinadas com a separação das suas frações por eletroforese representam uma informação acurada das suas concentrações plasmáticas totais (CAMPBELL, 2004). O padrão da separação inclui uma fração de pré-albumina em algumas espécies (como nos psittacídeos), albumina, alfa-globulina, beta-globulina e gama-globulina e são importantes no diagnóstico em bioquímica clínica para avaliar as respostas inflamatórias (KANEKO, et al., 1997; KERR, 2003).

Outras anormalidades que podem sugerir distúrbios hepáticos incluem hipoalbuminemia, hipoglicemia, hiperamonemia e diminuição dos fatores da coagulação, mas raramente são observados nas aves (CAMPBELL, 2004). Alterações significativas nas proteínas séricas foram observadas em aves inoculadas com cepa virulenta do vírus da doença de Newcastle. Com diminuição nos níveis de albumina e, conseqüentemente, diminuindo a concentração de proteínas totais. Não foi observada nenhuma alteração no nível das globulinas (RIVETZ et al., 1977). Isto pode demonstrar lesões hepáticas, pois o fígado é o órgão que sintetiza as proteínas, principalmente a albumina. Outra possível causa para a diminuição da albumina seriam as lesões em vísceras, principalmente do sistema digestório, com ulcerações intestinais e hemorragias. Estas lesões promovem perda de sangue e de albumina. A concentração sérica de albumina também pode ser reduzida por diminuição na ingestão de alimentos devido à anorexia (KANEKO et al., 1997).

$\mathrm{Na}$ insuficiência hepática há diminuição significativa dos valores das proteínas totais concomitantemente à diminuição da proporção albumina/ globulinas. Distúrbios gastrintestinais e renais, além de deficiências nutricionais também podem levar a hipoproteinemia severa. (LEWANDOWSKI et al., 1986; LUMEIJ, 1997). Em condições inflamatórias agudas ou crônicas, pode ocorrer um aumento na quantidade de proteínas totais, pela elevação das globulinas e diminuição da albumina. A diminuição da proporção albumina/globulinas pode ocorrer na inflamação, nas peritonites, aspergilose, psitacose e tuberculose, nefropatias e insuficiência hepática (LUMEIJ, 1997; JONES, 1999).

\subsection{Função muscular}

A creatina quinase (CK) é uma enzima músculo específica utilizada para avaliar a função muscular 
das aves (LUMEIJ, 1997; CAMPBELL, 2004). Os teores normais variam de 100 a $500 \mathrm{UI} / \mathrm{L}$. O aumento na sua concentração plasmática indica distúrbio muscular, intoxicação por chumbo, clamidiose, septicemias e miopatias por deficiência de vitamina E/selênio. $\mathrm{O}$ aumento marcante está relacionado com miopatia de contenção, nesta condição a atividade da AST não aumenta significativamente (CAMPBELL, 2004). Deve-se ter cuidado com injeções intramusculares com substâncias irritantes (doxiciclina, oxitetraciclina que deviam ser administradas via EV), pois aumentam as concentrações da creatina quinase (CK) (LUMEIJ, 1997; FUDGE, 2000a).

As micotoxinas neurotóxicas podem causar elevação das atividades séricas das enzimas musculares creatina quinase (CK), AST e lactato desidrogenase (LD). Estas alterações ocorrem pela atividade muscular intensa causada por tremores musculares e convulsões (PUSCHNER, 2002).

\subsection{Eletrólitos}

Concentrações normais de eletrólitos no plasma, líquido intersticial e linfa são necessárias para o funcionamento normal do potencial eletroquímico das membranas celulares e para a manutenção do compartimento hídrico do organismo em volumes corretos. Estes íons também estão relacionados com a regulação da pressão osmótica, equilíbrio hidro-eletrolítico, manutenção dos potenciais de membrana, transmissão dos impulsos nervosos e contração muscular, exercendo assim importantíssimo papel na homeostase do organismo (KANEKO et al., 1997; KERR, 2003).

Sódio e potássio são os eletrólitos mais comumente avaliados em medicina veterinária. No caso das aves, o papel desses eletrólitos para diagnóstico precisa ser melhor investigado (LEWANDOSWKI et al., 1986). O sódio é filtrado pelo glomérulo e, dependendo da necessidade osmótica, pode ser reabsorvido para o plasma ou secretado pelos túbulos renais para sua eliminação (CAMPBELL, 2004). O potássio é filtrado ativamente e excretado pelos rins. $\mathrm{Na}$ doença renal em aves, foram observadas hipercalemia e hiperfosfatemia, porém, hipofosfatemia e hipocalemia também foram reportados. $E$ aves com doença renal crônica perdem a habilidade de reter sódio, resultando em hiponatremia. Anormalidades que afetam as concentrações de aldosterona e o estado de hidratação do organismo (privação de água ou diarréia), também alteram os valores de sódio e potássio. As concentrações séricas de sódio nas aves variam entre 130 a $170 \mathrm{mEq} / \mathrm{L}$ e de potássio de 2,5 a 6 mEq/L (ROSS et al., 1978; LEWANDOSWKI et al., 1986; CAMPBELL, 2004)

O cálcio é um mineral de importância diagnós- tica em todas as espécies animais. Este mineral é importante na manutenção da atividade elétrica e também é um elemento estrutural importante nos ossos. Cerca de metade do cálcio plasmático está livre e esta é a porção ativa de cálcio (cálcio iônico), enquanto a outra metade encontra-se inativa, ligada à albumina (KERR, 2003), que é a forma geralmente mensurada. Nas aves os valores de cálcio variam entre 8 a $12 \mathrm{mg} / \mathrm{dL}$, mas aves em postura apresentam valores de 20 a $40 \mathrm{mg} / \mathrm{dL}$, possivelmente pelo aumento da demanda de cálcio para a formação da casca do ovo (ROSS et al., 1978). O cálcio para a formação da casca do ovo é derivado da absorção intestinal e da mobilização óssea. O nível de cálcio ionizado, nestes casos, permanece inalterado (CAMPBELL, 2004). O aumento das concentrações de cálcio iônico ocorre em respostas vacinais, pois o reconhecimento do antígeno feito pelas células $T$ receptoras é mediado pela ativação da calcioneurina. Este efeito foi observado em frangos de corte vacinados contra a coccidiose (ABBAS et al., 2000; SCHMIDT et al., 2006b). O aumento das concentrações de cálcio no soro também é observado em dietas com excesso de vitamina $D_{3}$ e em condições neoplásicas que provocam lesões ósseas. Os níveis de cálcio inferiores a $6 \mathrm{mg} / \mathrm{dL}$ resultam em tetania, principalmente em aves submetidas a estresse. Os distúrbios renais causam diminuição do cálcio sérico pela perda de proteínas, que leva a hipoalbuminemia ou pela diminuição da reabsorção do cálcio (LEWANDOSWKI et al., 1986).

Apesar da relação do metabolismo do cálcio e do fósforo no organismo, o valor diagnóstico do fósforo sérico nas aves é inconsistente (LEWANDOSWKI et al., 1986). Aves jovens, em crescimento tendem a apresentar valores mais elevados de fósforo quando comparadas com aves adultas. A hipofosfatemia é indicada por níveis sangüíneos inferiores a $5 \mathrm{mg} /$ $\mathrm{dL}$, que pode ocorrer pela deficiência de vitamina $\mathrm{D}_{3}$, terapia de longa duração com corticoesteróides e períodos prolongados de jejum. A hiperfosfatemia é indicada por concentração de fósforo superior a 7 $\mathrm{mg} / \mathrm{dL}$ e resulta de distúrbio renal severo pela diminuição da filtração glomerular, excesso de vitamina $\mathrm{D}_{3}$ que leva ao aumento da absorção intestinal de fósforo e pelo excesso de fósforo na dieta (LUMEIJ, 1997; CAMPBELL, 2004).

\section{CONSIDERAÇÕES FINAIS}

Nos últimos anos houve um aumento no atendimento na clínica médica de aves de companhia, e conseqüentemente, uma maior necessidade na qualidade dos serviços. Para isso, é necessário o conhecimento básico da anatomia e da fisiologia 
aviária para interpretação apropriada dos valores sangüíneos.

Apesar das limitações em relação à quantidade de sangue necessária para realizar provas diagnósticas e o volume de sangue obtido das aves, principalmente em animais jovens, essas condições não devem impedir que os testes sangüíneos sejam utilizados como ferramenta útil no monitoramento das diversas enfermidades que acometem as aves.

Os estudos dos parâmetros hematológicos e bioquímicos são essenciais para contribuir com o progresso da medicina aviária, com a realização de estudos que permitam a interpretação adequada das respostas do organismo e do acompanhamento de casos clínicos e de campo, para possíveis adoções de medidas visando uma melhora no diagnóstico e na produção industrial.

\section{REFERÊNCIAS}

ABBAS, A.K.; LICHTMAN, A.H.; POBER, J.S. Cellular and Molecular Immunology, $4^{\text {th }}$ edition, Philadelphia, W.B. Saunders, 2000, 533p.

AMAND, W.B. Avian Clinical Hematology and Blood Chemistry. In: FOWLER, M.E. Zoo and Wild Animal Medicine, $2^{\text {nd }}$ edition. Philadelphia, W.B. Saunders, 1986, p. 264-276.

ANDERSON, C.B. Determination of chicken and turkey plasma and serum protein concentrations using refractometry and the biuret method. Avian Diseases, v. 33, p. 93-96, 1989.

BIRGEL, E.H. Hematologia Clínica Veterinária. In: BIRGEL, E.H.; BENESI, F.J. Patologia Clínica Veterinária. São Paulo, SPMV, 1982, p. 2-34.

BOUNOUS, D. I.; STEDMAN, N.L. Normal Avian Hematology: Chicken and Turkey. In: FELDMAN, B.F.; ZINKL, J.G.; JAIN, N.C. Schalm's Veterinary Hematology. $5^{\text {th }}$ ed, Philadelphia, Lippincot, Williams \& Wilkins, 2000, p.1147-1154.

CAMPBELL, T.W. Clinical Chemistry of Birds. In: THRALL, M.A. Veterinary Hematology and Clinical Chemistry. Philadelphia, Lippincott, Williams \& Wilkins, 2004,. p. 479-492.

CHANG, C.F.; HAMILTON, P.B. Impaired phagocytosis by heterophils from chickens during aflatoxicosis. Toxicology and Applied Pharmacology, v.48, n.3, p. 459-466, 1979.
DEIN, F. J. Hematology. In: Clinical Avian Medicine, Philadelphia, W B Sauders, 1986, p.174-191.

FUDGE, A. M. Avian Complete Blood Count. In: FUDGE, A.M. Laboratory Medicine - Avian and Exotic Pets, W.B. Saunders, 2000a, p.9-18.

FUDGE, A. M. Avian Clinical pathology - hematology and chemistry. In: ALTMAN, R. B.; CLUBB, S. L.; DORRESTEIN, G. M. QUESENBERRY, K. Avian Medicine and Surgery. Philadelphia, W. B. Saunders, 1997, p. 142-157.

FUDGE, A. M. Avian Liver and Gastrointestinal Testing. In: FUDGE, A.M. Laboratory Medicine - Avian and Exotic Pets; W.B. Saunders, 2000b, p.47-55.

FUDGE, A. M; JOSEPH, V. Avian Complete Blood Count. In: FUDGE, A.M. Laboratory Medicine Avian and Exotic Pets; W.B. Saunders, 2000, p. 19-27.

GONZÁLEZ, F.H.D.; HAIDA, K.S.; MAHL, D.; GIANNESI, G.; KRONBAUER, E. Incidência de Doenças Metabólicas em Frangos de Corte no Sul do Brasil e Uso do Perfil Bioquímico Sangüíneo para o seu Estudo. Revista Brasileira de Ciência Avícola, v.3, n.2, 2001, p.141-147.

GREGORY, C.R. Urinary System. In: LATIMER, K.S.; MAHAFFEY, E.A.; PRASSE, K.W. Veterinary Laboratory Medicine - Clinical Pathology, 4th ed. Blackwell Publishing, p. 231-259, 2003.

JONES, M.P. Avian clinical pathology. Veterinary Clinics Exotic Animal Practice, v.2, p.663-687, 1999.

KANEKO, J.J.; HARVEY, J.W.; BRUSS, M.L. Clinical Biochemistry of Domestic Animals, $5^{\text {th }}$ ed., San Diego, Academic Press, 1997, 932p.

KERR, M.G. Exames Laboratoriais em Medicina Veterinária - Bioquímica Clínica e Hematologia, $2^{\mathrm{a}}$ edição, São Paulo, Roca, 2003. 436p.

KRAFT, H. Métodos de Laboratorio Clínico Em Medicina Veterinaria de Mamíferos Domésticos. Zaragoza, Editorial Acribia, 1998. 295p.

LATIMER, K.S.; BIENZLE, D. Determination and Interpretation of the Avian Leukogram. In: FELDMAN, B.F.; ZINKL, J.G.; JAIN, N.C. Schalm's Veterinary Hematology, $5^{\text {th }}$ ed., Philadelphia, Lippincott Williams \& Wilkins, 2000, p. 417-432. 
LEWANDOWSKI, A.H.; CAMPBELL, T.W.; HARRISON, G.J. Clinical Chemistries. In: HARRISON, G.J.; HARRISON, L.R. Clinical Avian Medicine, Philadelphia, W. B. Sauders, 1986. 717p.

LIERZ, M. Avian renal disease: pathogenesis, diagnosis and therapy. Veterinary Clinics Exotic Animal Practice, v. 6, p. 29-55, 2003.

LOCATELLI-DITTRICH, R.; GOUVEIA, F.C.; SCHMIDT, E.S.S. Leucograma, AST e GGT em codornas de criação industrial - Coturnix coturnix coturnix, com alterações nos heterófilos. Anais. XXVII Congresso Brasileiro de Medicina Veterinária, Águas de Lindóia, p. 10, 2000.

LUMEIJ, J.T. Avian Clinical Biochemistry. In: KANEKO, J.J.; HARVEY, J.W.; BRUSS, M.L. Clinical Biochemistry of Domestic Animals $5^{\text {th }}$ edition. San Diego, Academic Press, 1997. 932p.

MEYER, D.L.; COLES, E.H.; RICH, L.J. Medicina de Laboratório Veterinária: Interpretação e Diagnóstico. São Paulo, Roca, 1995. 308p.

PEROZO, F.; FERRER, J.; ALVARADO, M.; Haematological values in broiler chicks during long time - Low level exposure to Aflatoxin B-1 in Zulia State, Venezuela. Revista Cientifica-Facultad de Ciencias Veterinarias, v. 13 n.1, p. 59-64, 2003.

PUSCHNER, B. Mycotoxins. Veterinary Clinics of North America - Small Animal Practice, v. 32, p. 409-419, 2002.

REECE, W.O. Fisiologia dos Animais Domésticos, $12^{\mathrm{a}}$ ed. Rio de Janeiro, Guanabara-Koogan, 2006. $926 \mathrm{p}$.

RIVETZ, B.; BOGIN, E.; HORNSTEIN, K.; MERDINGER, M. Biochemical changes in fowl serum during infection with strains of Newcastle disease virus of differing virulence. Changes in serum proteins, uric acid, lipids and electrolytes. Research in Veterinary Science, v. 22, p. 285-291, 1977.

ROSS, J.G.; CHRISTIE, W.G.; HALLIDAY, W.G.; MORLEY JONES, R. Haematological and blood chemistry "comparison values" for clinical pathology in poultry. Veterinary Record v. 102, p. 29-31, 1978.
SCHMIDT. E.M.S.; LANGE, R.R.; RIBAS, J.M.; DACIUK, B.M. Parâmetros hematológicos de papagaio-de-peito-roxo (Amazona vinacea) e cuiúcuiú (Pionopsitta pileata) mantidos em cativeiro. In: XXIV Congresso Brasileiro da Associação de Clínicos Veterinários de Pequenos Animais, 2003, Belo Horizonte, Belo Horizonte: Anais... ANCLIVEPA, 2003, p. 100.

SCHMIDT, E.M.S.; PAULILLO, A.C.; ALFARO, D. M.; OLIVEIRA, E.G.; RIBAS, J.M.; SANTIN, E. Parâmetros hematológicos de faisões (Phasianus colchicus) em estação reprodutiva. Revista Brasileira de Ciência Avícola suplemento 8, p. 206, 2006a .

SCHMIDT, E.M.S.; PAULILLO, A.C.; ALFARO, D.M.; OLIVEIRA, E.G.; MANGRICH-ROCHA, R.M.V.; SANTIN, E. Parâmetros laboratoriais de frangos de corte vacinados contra a coccidiose. Revista Brasileira de Ciência Avícola suplemento 8, p. 207, 2006b .

SCHMIDT, E.M.S.; PAULILLO, A.C.; SANTIN, E.; LOCATELLI-DITTRICH, R.; OLIVEIRA, E.G. Hematological and serum chemistry values for the ring-necked pheasant (Phasianus colchicus): variation with sex and age. International Journal Poultry Science, v. 6, n.2, p. 137-139, 2007.

THRALL, M.A. Veterinary Hematology and Clinical Chemistry. Philadelphia, Lippincott, Williams \& Wilkins, 2004. 518p.

VOIGT, G.L. Conceptos y Técnicas Hematológicas para Técnicos Veterinarios. Zaragoza, Editorial ACRIBIA, 2003. 144p.

WINTROBE, M.M. The size and hemoglobin content of erythrocyte. Methods of determination and clinical application. Journal of Laboratory Clinical Medicine, v. 17, p. 899, 1932.

ZINKL, J. G. Avian Hematology. In: JAIN, N.C. Schalm's Veterinary Hematology. $4^{\text {th }}$ ed, Philadelphia, Lea \& Febiger, 1986, p.256-273.

Recebido para publicação:

$02 / 05 / 2007$

Aprovado:

$12 / 11 / 2007$ 